\title{
Analysis and Countermeasure Research on the Problems of Contemporary College Students' Life Education
}

\author{
Wang $\mathrm{Xu}^{1}$, and Chen Jingyi ${ }^{2}$ \\ ${ }^{1}$ Student Word Department, Jilin Engineering Normal University, Changchun 130052 , China \\ ${ }^{2}$ Party committee organization department, Jilin Engineering Normal University, Changchun \\ 130052 , China
}

\section{Keywords: College students; Life education; Problems; Countermeasures}

\begin{abstract}
College students' life education belongs to the category of life education. It has the commonality of ordinary life education, helps the normal development of life, and promotes the development of life. However, with the rapid development of higher education in our country, while the number of university students has soared, it has repeatedly appeared that some college students do not respect life. Whether it is killing or committing suicide, the appearance of every case is shocking. The reason why these higher education students do not cherish their lives deserves our deep thinking. This article starts from the life education course in colleges and universities, infiltration education for contemporary college students; strengthen the construction of campus cultural activities, create a campus culture of humanistic feelings; carry out social practice activities, experience the value of life and other measures to solve the outstanding problems of life education.
\end{abstract}

\section{Introduction}

As a special group of society, college students place high expectations on them. With the rapid development of economy, technology, and society, college students have brought unprecedented opportunities. At the same time, they have also brought pressure on employment, emotions, academics, and society. However, contemporary college students are at a crucial stage in shaping their personality with life as their core. It is undoubtedly important for them to establish their awareness of protecting their lives and pursuing the right values of life values. This article starts from the problems existing in the life education of contemporary college students, mainly because the utilitarianization of higher education is too serious, and life education has not received enough attention. College students lack beliefs and life is lost, their psychological pressure capacity is low, and they lack understanding of life; the curriculum system is not sound enough, lacks systematization and diversification; the form of life education is simple and boring, the practice is not enough, and life is relatively poor. There is a shortage of teachers in life education, and the level of teaching and the quality of teaching needs to be improved; there is a lack of effective educational cooperation among families, schools, and society. To this end, we must earnestly raise awareness of the importance of life education for college students, inspire college students to pursue human business, and build life education courses for college students.

\section{Problems in Life Education of Contemporary College Students}

At present, most college students in our country have a positive and progressive attitude toward life. The understanding of the concept of life is basically correct. However, there are still a small number of undergraduates who do not have the ability to protect themselves, their attitudes to life are too negative, they do not feel the joy of life, they cannot face life pressures correctly, and they have deviations from themselves, others and society. It is mainly manifested in "there is a misunderstanding of life, a low sense of well-being in life, an increase in suicidal thoughts, a life without fun and meaning, a practical and utilitarian life value, and a setback in life. I would rather choose to vent myself or help others. There is a lack of trust and egoism in other living entities." Therefore, it is extremely urgent to analyze the problems in life education of college students. 
The Curriculum Construction of Life Education is Lagging Behind. The establishment of a special life education course is the most important channel and the most effective and direct method for the life education of college students. In mainland China, the curricula of colleges and universities are limited and the construction of life education curriculum lags behind. For a long time, school education in our country has been the main goal of imparting knowledge, learning culture and skills. It has neglected the development of students' moral qualities and the development of their abilities. It lacks guidance and reflections on common problems and common cases. Although in the courses of ethics, philosophy, psychology, ideological and political education theory, and pedagogy, students can gain some knowledge about life education.

Campus Cultural Activities lack Guidance for life Education. The lack of guidance for life education in college campus cultural activities is one of the problems in the life education of college students. At present, the campus cultural activities in China's colleges and universities rarely take the theme of life education. More themes are ideological and political education, moral and legal cultivation, professional knowledge and skills training and cultural quality education. For a long time, campus cultural activities have often been restricted by multiple conditions such as organization, funding, venues, and personnel. Various activities have flown into forms. The phenomenon of "false, empty, and large" has appeared. Like a gust of wind, it looks like it's going through the court. Not only did it fail to achieve the expected results, but it also increased the burden on students and made it difficult to display the student's subjectivity and enthusiasm.

Life Education and Social Practice have not been Effectively Combined. At present, social practice activities in Chinese universities are mainly divided into four categories. The first is research-based practice, which is mainly manifested through activities such as teaching practice, professional practice, research, and popularization of science and technology. The second type is the service-oriented practice of taking the country to the countryside, entering the community, and serving the society as the core. The third type is cumulative practice. The most representative ones are practical activities such as work-study education and factory practice. The fourth is tuotuo practice. The current entrepreneurship training, career exploration, and career education advocated by the Ministry of Education fall into this category. In these practical activities, there are few practical projects on life education topics. Although some social practice activities also involve the content of life education, they are relatively single and scattered and do not form an independent system.

\section{The Challenge of Life Education for Contemporary College Students}

The Authority of Life Educators is Weakened. Teacher authority refers to the power and prestige that a teacher possesses in an educational activity to convince others. Through the authority of the educator, the educated can help overcome the selfishness and self-cultivation. It can achieve the social purpose of training individuals into a new talent. For life educators, their authority also determines the effectiveness of life education. Under the concept of traditional education philosophy, the knowledge of life education is objective, stable and closed, universal and value neutral, and the nature of knowledge determines the authority of teachers in life education. In modern times, knowledge is diverse and open and constantly constructed, which leads to the elimination of knowledge authority, and thus the authority of teachers is also weakened. Teachers are no longer absolute authority, and the dominance of education is weakened, leading to an increase in the difficulty of life education.

The Main Idea of Life Education is Impacted. In education, the mainstream ideology refers to a normal ideological concept that is consistent with the laws of educational development and social needs and is welcomed by the majority of educators. The main concepts of life education in China are generally the following. Firstly, Marxist philosophy of life philosophy. For example, life is a process of natural existence, social existence or realization of human freedom and overall development. The second is the Chinese classical philosophy of life, such as Confucianism's "Benevolence, Righteousness, Wisdom, Literacy, etc." The third is China's modern education ideas, such as Tao Xingzhi's "life is education". However, with the development of the economy and 
society, undergraduates' ideas have become more and more open. They believe that the mainstream ideas of life education are also pluralistic and dynamic. Coupled with the tediousness and formality of the current methods of teaching life education, the modern university students are disgusted and inconsistent with these mainstream education ideas.

The Traditional Life Education Curriculum has Flaws. The main goal of the traditional life education curriculum is to teach students to master the knowledge of life and the skills for survival. The curriculum is relatively simple. It mainly focuses on the "infiltration" life education curriculum. The curriculum organization is mainly carried out based on the knowledge logic. The teaching methods are mainly discussion and speculation. The curriculum content is relatively fragmented. It is seldom listed in the university education and teaching plan. The contents of education and teaching are not perfect, and a complete system has not been formed. This is not conducive to the effective development of life education for contemporary college students. This is because the questioning, reflection, and access to the meaning of life are the ultimate pursuit of life education for college students. Therefore, the design of the curriculum should be a combination of "infiltration courses", "integrated courses" and "special courses". Curriculum content should be selected from the four aspects of natural life, spiritual life, social life and value of life. At the same time, the development of life education should be a combination of cognition and practice to achieve "unity of knowledge and action" and "unification of knowledge and practice."

\section{Countermeasures to Solve the Problem of Life Education for Contemporary College Students}

Strengthen the Construction of Teachers. Teachers are the souls who carry out all kinds of education work. In the process of life education in colleges and universities, we must strengthen the construction of teachers and ensure the smooth progress of life education. At present, the professional teacher team for life education is still relatively small, and counselors do not possess relevant knowledge. In order to carry out life education more effectively and smoothly, a group of professional teachers should be trained to guide students' understanding and understanding of life further.

Nurturing a group of life education teachers, life education has received more and more attention in colleges and universities in recent years, but the status and achievements have not been significant, and are closely related to the professionalism of our teachers. In many colleges and universities, teachers and counselors responsible for psychological counseling act as life teachers. In fact, psychological counseling and life education are still somewhat different. Life education focuses more on education of life health, life value, and life responsibility of university students. In the face of some special cases, psychological counseling often cannot accurately grasp the nature of the problem. Therefore, it is possible to select professional teachers from psychological counseling teachers and counselors.

Systematic Learning and Training Brings Life Education into College Classrooms. The content of life education for college students involves such a wide range that only a single teaching method can't achieve a very good educational effect. It should be through the full cooperation of society, schools and families, and then through the continuous innovation of the educational model to expand life education. Because life is colorful, the form of life education should also be colorful. In the process of life education, teachers must change the traditional way of teaching. They can't blindly indoctrinate. They can try some new teaching modes to allow students to experience life and thus comprehend life. For example, seminars, debates, social practices, etc., to guide students in conscious life learning.

Since the university students' life education was launched, major universities and colleges are constantly innovating their teaching methods and models in order to make life education more effective. Boring classrooms make it easy for college students to feel bored and bored. Therefore, life education methods need to be diverse and flexible. Combining the content of life education with the contents of other courses, it is no longer "on the life of life," and ideological and political theory courses and psychological counseling courses have become important carriers of life education. 
Strengthen the Curriculum Practice Experience. In life education in colleges and universities, students should be provided with a platform for activities. The first is to organize students into the nursing home, into disabled schools, and into communities and rural areas. The second is to invite police and firewfighters to organize students to conduct fire drills and learn self-rescue methods in critical situations. Third, we can invite people who have been suicidal for the rest of their lives but who have had a life-threatening attitude toward suicide, but who now love life, come to the school, organize students to hold seminars with them, and exchange ideas from the close to the heart to solve problems for college students. The fourth is to select student representatives and share their own stories with classmates. Some students may not initially adapt to university life due to family conditions, introvertedness, etc., but they gain a lot during the school through their own efforts. There are also some active struggles with the disease. The typical cases can help students realize the meaning of life.

Create a Warm and Welcoming Home Environment. A good and warm family environment will bring a sense of security to college students. Even if they feel unsatisfied in their studies or life, they can still return to their families to seek help. Therefore, creating a warm and harmonious family atmosphere for college students is a good protection for them. Parents should try to avoid quarrels in front of their children during normal life. Bad emotions can cause infections in children. In some families with intense parental relationships, the child's personality tends to be more autistic, he does not want to communicate with others, does not trust other people, and tends to become more irritated when he grows up. Parents should try to make them feel the love between parents and their love for children during their growing up. The whole family loves each other. When the children enter the university and face a strange environment, they will have hope for life.

\section{Summary}

The inheritance of life is endless and the research on life education will continue to develop. Everyone should have a heart of gratitude to life, cherish love for life, and make their own lives glow. College students are a group with distinct personality. Their physical and mental development is the concern of the whole society. Therefore, the problems in the life education of contemporary college students have also attracted attention from many parties. How to help college students cherish life, understand life, and have a correct view of life is the core issue of life education for college students, and it is also the core content of the entire article. It is hoped that this paper will enable more people to pay attention to the life education of college students and help college students to correctly understand life and establish a correct view of life, so that their young lives will be full of vigor, radiance, and power.

\section{Fund Project}

Key project of jilin province education science 13th five-year plan 2017"Analysis and countermeasure research on education problem of conremporary college students'life "(ZD17127) The host: Chen jingyi

\section{References}

[1] Xin J I, Chen L J. Problem Analysis and Countermeasures of Contemporary College Students' Outlook on Life Education[J]. Journal of Liaoning Provincial College of Communications, 2014.

[2] Yu Z Q, Yang Z G. A Brief Analysis on the Causes and the Countermeasures of Crisis of Contemporary College Students' Interpersonal Integrity[J]. Science Education Article Collects, 2012, 12(4):4364-4373.

[3] Xie P G, Qin Y Z. Analysis and Countermeasures of the Current Situation of the Sex Education of the Contemporary College Students[J]. Education Teaching Forum, 2016.

[4] Liu X. A Brief Analysis on the Present Situation and Countermeasures of Contemporary College 
Students' Life Values[J]. Science Education Article Collects, 2017.

[5] Leng N, Fu H, Liu C. An Analysis of the Reasons and Countermeasures of Contemporary College Students' Dishonesty in Examinations[J]. Science Education Article Collects, 2017.

[6] Wang F, Song X. Problems and Countermeasures on the Spiritual Life of Contemporary College Students[J]. Meitan Higher Education, 2016.

[7] Wang J K. The Analysis of the Causes and Countermeasures of Mental Health Problems of Contemporary College Students_-Based on the Actual Work of Counselors[J]. Education Teaching Forum, 2017.

[8] Guo Z. Analysis of the ideological and political situation of contemporary college students and the countermeasures[J]. Journal of Jiamusi Vocational Institute, 2017.

[9] Zhu D, Marxism S O, University X M. The Countermeasures of Strengthening Contemporary College Students' Marxism Belief Education under the Background of Plural Cultures[J]. Journal of the Party School of Shengli Oilfield, 2017.

[10] Zhang S, Chen D, Li W. Employment Situation Analysis and Countermeasures of Contemporary College Students[C]// International Conference on Education Technology and Information System. 2014.

[11] Ren F, Zhang X. On Contents and Countermeasures of Contemporary College Students' Social Moral Education[J]. Journal of Qingyuan Polytechnic, 2013.

[12] Yan L I, Huang Y, Wang J, et al. Analysis and Countermeasures of Psychological Problems of Contemporary College Students[J]. Guide of Science \& Education, 2014.

[13] Yang Y Y, Gao X L. Analysis of the Current Situation and Countermeasures of Contemporary College Students' Learning__ Taking a University in Shanghai as an Example[J]. Education Teaching Forum, 2017.

[14] Yao Q, Zhang X. The Challenge and Countermeasures of Cultivating the Cultural Self-confidence of Contemporary College Students__Cultural Identity Based Perspective[J]. Theory Research, 2018. 